\title{
Speed Control of 5-Phase Induction Motor Drive using Model Reference Adaptive System
}

\section{M.Sowmiya and G.Renuka Devi}

Abstract - This paper presents the Speed Control of 5-Phase Induction Motor Drive using Model Reference Adaptive System. Multiphase motors provides lower torque pulsation, reduced current per phase without increasing the voltage per phase, reduced harmonic current, greater reliability, fault tolerance and minimal de-rating at occurrence of fault. A detailed Model Reference Adaptive System of 5-phase drive is elaborated in this paper. This method is an effective speed estimation technique that involves relatively easy implementation with high speed of adaptation over a wide range of applications. A dq-axis model of five phase induction motor fed by a five-phase inverter is developed and the proposed MRAS-based sensor less vector control drive has been simulated and results are presented to illustrate its performance.

Keywords - dq-axis model, five-phase induction motor drive indirect field oriented control, model reference adaptive system, matlab/simulink

\section{INTRODUCTION}

ECENT years induction motors with three-phase windings are normally used, since the standard power

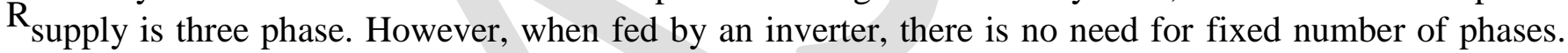
Including some other phases being possible and advantageous [1] of a multi-phase machine can operate with reduced torque pulsations, reduced harmonic currents, increased current per phase without the need to increase the phase voltage, increased torque/ampere relation for the same volume of the machine, that is a multi-phase machines can develop torque using not only the fundamental, but also using higher harmonics of the air gap field [2]. Another important aspect of machines with a higher number of phases is their improved reliability. They are applicable in areas where high power and reliability is demanded such as electric/hybrid vehicles, aerospace application, warship, submarine propulsion and circulation pumps in nuclear power plants. Identifiable merits and application it is necessary and prudent to investigate the performance of multiphase drives. A multi-phase induction motor can only be fed by a multiphase inverter. Number of phases in the inverter should be equal to the number of stator windings of the induction motor. Pulse to the switches of the inverter can be produced by various switching strategies such as PWM, SPWM, SVPWM etc., [3-7].Indirect field-oriented control (IFOC) is the most popular method of obtaining high performance in induction motor drives. IFOC induction motor drives are very popular in industrial application due to their relative simple configuration [8-10]. An incremental shaft-mounted speed encoder is required for closed loop speed control in both vector and

M.Sowmiya , Research Scholar, Department of Electrical and Electronics Engineering,College of Engineering, Anna University, Chennai- - 600025 (email: sowmiyavision2020@gmail.com).

Dr. G. Renuka Devi, Associate Professor, Department of Electrical and Electronics Engineering, Manakula Vinayagar Institute of Technology, Puducherry, India (e-mail: renukadeviayyappan@gmail.com). 
scalar controlled drives. A speed encoder is undesirable in a drive because it adds cost and reliability problems, besides the need for a shaft extension and mounting arrangement. It is possible to estimate the speed from machine terminal voltages and currents[11]. Model Reference Adaptive System (MRAS) based sensor less vector controlled drives are commercially available without parameter variation problem, particularly near zero speed and increased accuracy of speed estimation [12-14].

This paper focus on the development of simulation model of MRAS based 5-phase induction motor by a simple approach of utilizing the built in blocks of matlab/simulink environment.

\section{FIVE- PHASE INVERTER}

A five phase voltage source inverter is shown in Fig.1. A dc voltage source and switching devices are assumed to be ideal. There are five legs and each contributing one of the five phases. The switches can take either 1 or 0 value based on the state of upper or lower switch. In SPWM five-phase sinusoidal reference signal is compared with high frequency triangular carriers. A suitable modulation index that results in lesser harmonics at the output is chosen generate pulse to the inverter.

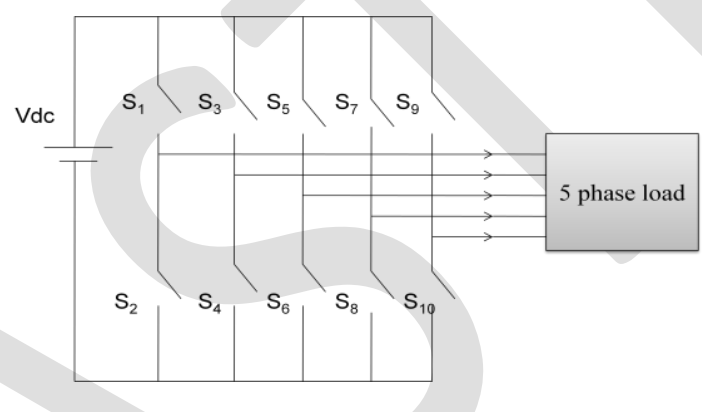

Fig.1. Five phase inverter

Utilization of more than three-phases enables splitting of the power across a larger number of inverter legs, thus enabling use of semiconductor switches of lower rating.

\section{FIVE PHASE INDUCTION MOTOR}

Fig.2 shows the Five- phase inverter fed five phase induction motor load. A five phase motor involves five stator windings with a phase difference of $72^{\circ}$ degree. An isolated neutral five-leg inverter configuration is used to drive a star-connected five-phase squirrel-cage induction motor. As the phase number increases stator excitation in the machine produces a field with a lower space-harmonic content, hence the efficiency is higher.

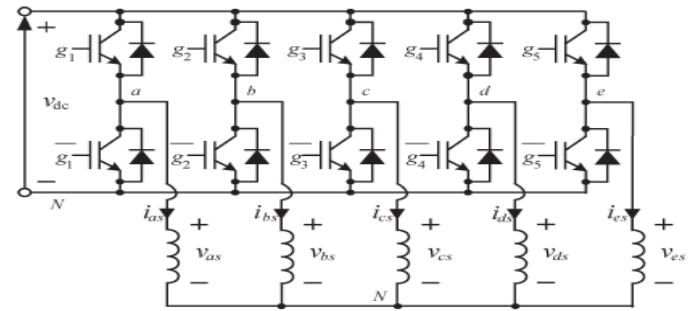

Fig.2. Five- phase inverter fed five phase induction motor 
Per phase equivalent circuit of the induction machine is valid only for the steady- state condition. In an adjustable speed drive, the machine normally constitute an element within a feed- back loop, and therefore is transient behavior has to be taken into account.

\section{MODELING OF 5Ф INDUCTION MOTOR}

High performance drive control is based on the dynamic d-q model of the machine. The five phase machine can be represented as a two phase equivalent with $d_{s}-q_{s}$ corresponding to stator direct and quadrature axes that are fixed on the stator axis and $\mathrm{d}_{\mathrm{r}}-\mathrm{q}_{\mathrm{r}}$ corresponding to rotor direct and quadrature axes that are rotating with a fixed speed of the rotor axis. The effect of time varying inductance can be eliminated by referring the stator and rotor variables to a common reference frame which rotates at any speed. A five phase induction motor can be modeled by the following steps as follows

A $5 \Phi$ inverter with its pulse given through SPWM technique is used to provide a $5 \Phi$ supply to the induction motor as

Where,

$$
\begin{aligned}
& V_{a}=\mathrm{V} \cos \theta_{\mathrm{e}} \\
& V_{b}=\mathrm{V} \cos \left(\theta_{\mathrm{e}}-2 \mathrm{a}\right) \\
& V_{c}=\mathrm{V} \cos \left(\theta_{\mathrm{e}}-3 \mathrm{a}\right) \\
& V_{d}=\mathrm{V} \cos \left(\theta_{\mathrm{e}}-4 \mathrm{a}\right) \\
& V_{e}=\mathrm{V} \cos \left(\theta_{\mathrm{e}}-4 \mathrm{a}\right)
\end{aligned}
$$

To transform the $5 \Phi$ stationary reference frame variables to $2 \Phi$ stationary reference frame variables. The first two rows of the matrix in (2) define variables that will lead to fundamental flux and torque production. The next and last row defines the negative and zero sequence components respectively that do not contribute to torque production when sinusoidal distribution of the flux around the air-gap is assumed.

$$
a=\frac{2 \pi}{5}, \theta_{\mathrm{e}}=\int \omega_{\mathrm{e}}
$$

$$
\left.\left[\begin{array}{l}
V_{q s}{ }^{s} \\
V_{d s}{ }^{s} \\
V_{x s}{ }^{s} \\
V_{y s}{ }^{s} \\
V_{0 s}{ }^{s}
\end{array}\right]=\sqrt{\frac{2}{5}}\left[\begin{array}{ccccc}
1 & \cos \alpha & \cos 2 \alpha & \cos 3 \alpha & \cos 4 \alpha \\
0 & \sin \alpha & \sin 2 \alpha & \sin 3 \alpha & \sin 4 \alpha \\
1 & \cos 2 \alpha & \cos 4 \alpha & \cos 6 \alpha & \cos 8 \alpha \\
0 & \sin 2 \alpha & \sin 4 \alpha & \sin 6 \alpha & \sin 8 \alpha \\
\frac{1}{\sqrt{2}} & \frac{1}{\sqrt{2}} & \frac{1}{\sqrt{2}} & \frac{1}{\sqrt{2}} & \frac{1}{\sqrt{2}}
\end{array}\right] *\left[\begin{array}{c}
V_{a} \\
V_{b} \\
V_{c} \\
V_{d} \\
V_{e}
\end{array}\right] \quad\right)
$$

To transform the stator variables in stationary reference frame to synchronous reference frame. In this transformation the q-axis of the voltage variable is aligned to zero and only the d-axis variable is present hence it is easily controlled. 


$$
\left[\begin{array}{c}
V_{d s}^{e} \\
V_{q s}^{e}
\end{array}\right]=\left[\begin{array}{cc}
\cos \theta_{e} & \sin \theta_{e} \\
-\sin \theta_{e} & \cos \theta_{e}
\end{array}\right] *\left[\begin{array}{c}
V_{d s} \\
V_{q s}^{s}
\end{array}\right]
$$

The stator and the rotor voltage equations in synchronous reference frame are given by equations (3) and (4)

$$
\begin{aligned}
& V_{d s}{ }^{e}=\mathbf{i}_{d s}{ }^{\mathrm{e}} \mathbf{R}_{s}+\frac{\mathrm{d}}{\mathrm{dt}} \psi_{d r}{ }^{e}-\omega_{\mathrm{e}} \psi_{q s}{ }^{e} \\
& V_{q s}{ }^{e}=\mathbf{i}_{q s}{ }^{\mathrm{e}} \mathbf{R}_{s}+\frac{\mathbf{d}}{\mathrm{dt}} \psi_{q s}{ }^{e}+\omega_{\mathrm{e}} \psi_{d s}{ }^{e} \\
& V_{d r}{ }^{e}=\mathrm{i}_{d r}{ }^{\mathrm{e}} \mathrm{R}_{r}+\frac{\mathrm{d}}{\mathrm{dt}} \psi_{d r}{ }^{e}-\left(\omega_{\mathrm{e}}-\omega_{\mathrm{r}}\right) \psi_{q r}{ }^{e} \\
& V_{q r}{ }^{e}=\mathrm{i}_{q r}{ }^{\mathrm{e}} \mathrm{R}_{r}+\frac{\mathrm{d}}{\mathrm{dt}} \psi_{q r}{ }^{e}+\left(\omega_{\mathrm{e}}-\omega_{\mathrm{r}}\right) \psi_{d r}{ }^{\mathrm{e}}
\end{aligned}
$$

Rearranging the above equations (4) and (5) we get the flux equations are

$$
\begin{aligned}
& \psi_{d s}{ }^{\mathrm{e}}=\int V_{d s}{ }^{\mathrm{e}}-\mathrm{i}_{d s}{ }^{\mathrm{e}} \mathrm{R}_{s}+\omega_{\mathrm{e}} \psi_{q s}{ }^{e} \\
& \psi_{q s}{ }^{\mathrm{e}}=\int V_{q s}{ }^{e}-\mathrm{i}_{q s}{ }^{\mathrm{e}} \mathrm{R}_{s}-\omega_{\mathrm{e}} \psi_{d s}{ }^{\mathrm{e}} \\
& \psi_{d r}{ }^{\mathrm{e}}=\int V_{d r}{ }^{\mathrm{e}}-\mathrm{i}_{d r}{ }^{\mathrm{e}} \mathrm{R}_{r}+\left(\omega_{\mathrm{e}}-\omega_{\mathrm{r}}\right) \psi_{q r}{ }^{e} \\
& \psi_{q r}{ }^{\mathrm{e}}=\int V_{q r}{ }^{\mathrm{e}}-\mathrm{i}_{q r}{ }^{\mathrm{e}} \mathrm{R}_{r}-\left(\omega_{\mathrm{e}}-\omega_{\mathrm{r}}\right) \psi_{d r}{ }^{\mathrm{e}}
\end{aligned}
$$

Current expression in terms of flux linkage and leakage inductance of the motor is

$$
\begin{aligned}
& i_{q s}^{e}=\frac{\psi_{q s}^{e}\left[L_{l r}+L_{m}\right]-L_{m} \psi_{q r}^{e}}{\left(L_{l s} L_{l r}+L_{l s} L_{m}+L_{m} L_{l r}\right)} \\
& i_{d s}^{e}=\frac{\psi_{d s}^{e}\left[L_{l r}+L_{m}\right]-L_{m} \psi_{d r}^{e}}{\left(L_{l s} L_{l r}+L_{l s} L_{m}+L_{m} L_{l r}\right)} \\
& i_{q r}{ }^{e}=\frac{\psi_{q r}{ }^{e}\left[L_{l s}+L_{m}\right]-L_{m} \psi_{q s}{ }^{e}}{\left(L_{l s} L_{l r}+L_{l r} L_{m}+L_{m} L_{l s}\right)} \\
& i_{d r}{ }^{e}=\frac{\psi_{d s}^{e}\left[L_{l s}+L_{m}\right]-L_{m} \psi_{d s}{ }^{e}}{\left(L_{l s} L_{l r}+L_{l r} L_{m}+L_{m} L_{l s}\right)}
\end{aligned}
$$

Transformation of stator current in synchronous reference frame to stationary reference frame as

$$
\left[\begin{array}{c}
i_{d s}{ }^{s} \\
i_{q s}{ }^{s}
\end{array}\right]=\left[\begin{array}{cc}
\cos \theta_{e} & -\sin \theta_{e} \\
\sin \theta_{e} & \cos \theta_{e}
\end{array}\right] *\left[\begin{array}{c}
i_{d s}{ }^{e} \\
i_{q s}{ }^{e}
\end{array}\right]
$$


To obtain the five phase stator current from the stator currents in stationary reference frame by $2 \Phi$ to $5 \Phi$ transformation is represented by

$$
\begin{aligned}
& i_{a}=i_{q s}{ }^{s} \cos \theta_{e}+i_{d s}{ }^{s} \sin \theta_{e} \\
& i_{b}=i_{q s}{ }^{s} \cos \left(\theta_{e}-\alpha\right)+i_{d s}{ }^{s} \sin \left(\theta_{e}-\alpha\right) \\
& i_{c}=i_{q s}{ }^{s} \cos \left(\theta_{e}-2 \alpha\right)+i_{d s}{ }^{s} \sin \left(\theta_{e}-2 \alpha\right) \\
& i_{d}=i_{q s}{ }^{s} \cos \left(\theta_{e}-3 \alpha\right)+i_{d s}{ }^{s} \sin \left(\theta_{e}-3 \alpha\right) \\
& i_{e}=i_{q s}{ }^{s} \cos \left(\theta_{e}-4 \alpha\right)+i_{d s}{ }^{s} \sin \left(\theta_{e}-4 \alpha\right)
\end{aligned}
$$

Electromechanical torque and rotor speed of the five phase induction motor is obtained by (10) and (11) respectively

$$
\begin{aligned}
& T_{e}=p * L_{m} *\left(i_{q s} i_{d r}-i_{d s} i_{q r}\right) \\
& =p *\left(\psi_{q s} i_{d r}-\psi_{d s} i_{q r}\right) \\
& \omega_{r}=\int \frac{p}{2} * \frac{\left(T_{e}-T_{l}-B\right)}{J} d t
\end{aligned}
$$

\section{INDIRECT FIELD ORIENTED CONTROL}

IFOC scheme as for a three-phase induction machine are directly applicable to a multiphase induction machine regardless of number of phases except that the co-ordinate transformation has to produce an n-phase stator current or voltage references. It allows very precise and rapid control of the electromechanical torque produced by an induction machine. Operation of the controller can be obtained from Fig.3. It is seen that reference speed is compared with the estimated speed from MRAS and the error signal is given to a speed controller. A PI controller whose gain constants are tuned to produce pulses for obtaining desired speed. Reference currents $\mathrm{i}_{\mathrm{q}}{ }^{*}$ and $\mathrm{i}_{\mathrm{d}}{ }^{*}$ using the below equations (12) and (13)

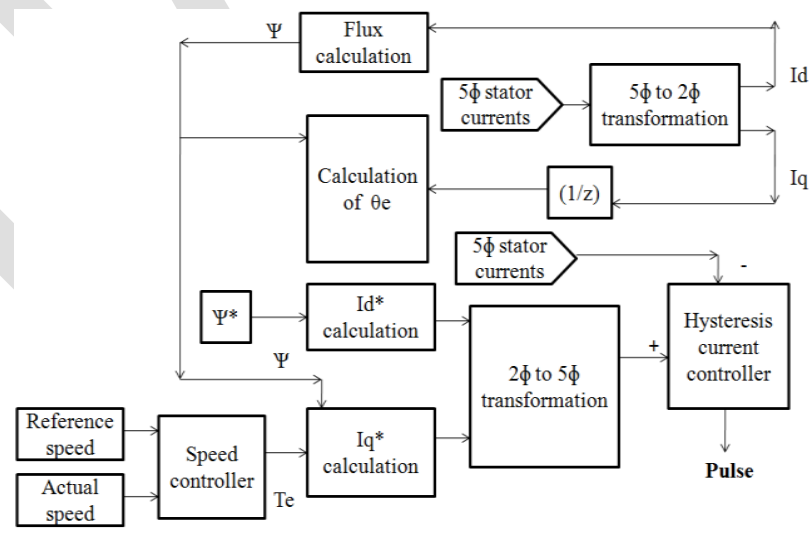

Fig.3. IFOC controller for a five phase induction motor 


$$
\begin{gathered}
i_{q}^{*}=\left(\frac{2}{5}\right) *\left(\frac{2}{p}\right) *\left(\frac{L_{r}}{L_{m}}\right) *\left(\frac{T_{e}}{\psi}\right) \\
\mathbf{i}_{\mathrm{d}}^{*}=\left(\frac{\psi^{*}}{L_{m}}\right)
\end{gathered}
$$

The reference flux linkage $\psi^{*}$ is commanded to be 0.96 and $\psi$ is obtained from the equation (14)

$$
\psi=\left(\frac{L_{m} * i_{d}}{1+T_{r} . s}\right)
$$

Here $i_{d}$ is the actual $d$-axis stator current. The currents $i_{d}$ and $i_{q}$ obtained through transformation of actual stator currents of the drive from equation (8)

$T_{r}$ is the time constant that depends upon the machine parameters $L_{r}$ and $R_{r}$

$$
T_{r}=\left(\frac{L_{r}}{R_{r}}\right)
$$

The electrical or field angle $\theta_{\mathrm{e}}$ required for the transformations is calculated by the following equation

$$
\theta_{e}=\int\left(\omega_{r}+\omega_{m}\right) d t
$$

Where $\omega_{m}$ is the rotor mechanical speed and $\omega_{r}$ the rotor electrical speed and it is given by

$$
\omega_{r}=\left(\frac{L_{m} * i_{q}}{\psi_{r} * T_{r}}\right)
$$

\section{SPEED ESTIMATION}

Sensor less vector control involves estimation of speed by MRAS. Flux based MRAS, back electromotive force based MRAS, reactive power based MRAS and Stator current based MRAS are more popular. Flux MRAS is stable in all the four quadrants. However, the pure-integrator which is used in the voltage model and related problems are major drawback. Stator current and back-emf-based MRAC depend on many machine parameters. They also suffers from deteriorating performance at low speed due to the presence of derivative operator, this lowers the signal-to-noise ratio.

A reactive power-based MRAS (X-MRAS) overcomes all such problems but at the cost of losing stability in the regenerative mode of operation. It uses two models, model that does not involve the quantity to be estimated is considered as reference model. The model that has the quantity to be estimated 
involved is considered as adaptive model. Output of the adaptive model is compared with reference model, and the difference is used to drive suitable adaptive mechanism whose output is the quantity to be estimated (the rotor speed). The adaptive mechanism should be designed to assure the stability of the control system. MRAS leads to relatively easy implementation with high speed of adaptation for a wide range of applications.

\section{A) Formulation of $X-M R A S$ :}

The induction motor stator voltages in the synchronously rotating reference frame can be expressed as

$$
\begin{aligned}
& v_{q s}=\left[R_{s} i_{q s}+\omega_{e} \sigma \cdot L_{s} \cdot i_{d s}+p \sigma \cdot L_{s} \cdot i_{q s}+\left(\frac{L_{m}}{L_{r}}\right) *\left(\omega_{e} \psi_{d r}+p \psi_{q r}\right)\right] \\
& v_{d s}=\left[R_{s} i_{d s}-\omega_{e} \sigma \cdot L_{s} i_{q s}+p \sigma \cdot L_{s} \cdot i_{d s}-\left(\frac{L_{m}}{L_{r}}\right) *\left(\omega_{e} \psi_{q r}-p \psi_{d r}\right)\right]
\end{aligned}
$$

$$
18
$$

Instantaneous value of $\mathrm{X}\left(\right.$ i.e. $\left.v^{*} \times i^{*}\right)$ is defined as

$$
X_{1}=V_{d s} * I_{q s}+V_{q s} * I_{d s}
$$

Substituting the values of $v_{s q}$ and $v_{s d}$, the instantaneous value of $\mathrm{X}$ becomes

$$
\begin{aligned}
& X_{2}=\left[R_{s} i_{q s}+\omega_{e} \sigma \cdot L_{s} i_{d s}+p \sigma \cdot L_{s} i_{q s}+\left(\frac{L_{m}}{L_{r}}\right) *\left(\omega_{e} \psi_{d r}+p \psi_{q r}\right)\right] * i_{s d} \\
& +\left[R_{s} i_{d s}+\omega_{e} \sigma \cdot L_{s} i_{q s}+p \sigma \cdot L_{s} i_{d s}+\left(\frac{L_{m}}{L_{r}}\right) *\left(\omega_{e} \psi_{q r}+p \psi_{d r}\right)\right] * i_{s q}
\end{aligned}
$$

For a rotor flux-oriented drive, substituting $\psi_{r d}=L_{m} * i_{s d}$, and $\psi_{r q}=0$, the simplified expression of $\mathrm{X}_{3}$ becomes

$$
\begin{aligned}
& X_{3}=\left[R_{s} i_{q s}+\omega_{e} \sigma \cdot L_{s} \cdot i_{d s}+\left(\frac{L_{m}}{L_{r}}\right) *\left(\omega_{e} \psi_{d r}\right)\right] * i_{s d}+ \\
& {\left[R_{s} i_{d s}-\omega_{e} \sigma \cdot L_{s} \cdot i_{q s}-\left(\frac{L_{m}}{L_{r}}\right) *\left(\omega_{e} \psi_{q r}\right)\right] * i_{s q}} \\
& X_{4}=\omega_{e}\left(L_{s} \cdot i_{d s}{ }^{2}+\sigma \cdot L_{s} \cdot i_{q s}{ }^{2}\right)+2 * R_{s} * i_{d s} * i_{q s}
\end{aligned}
$$




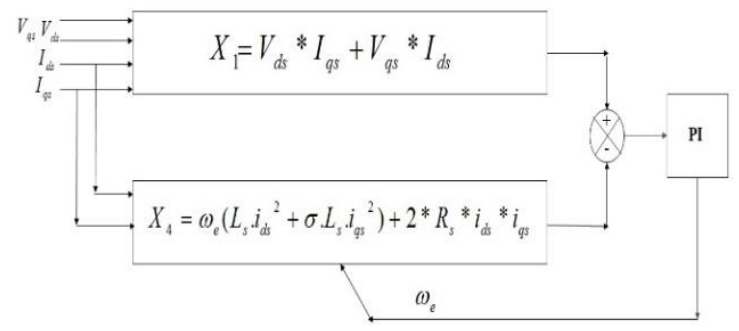

Fig.4. Basic model of X-MRAS

The expression of $X_{1}$ is independent of rotor speed. Hence, it is selected as reference model. $X_{2}, X_{3}$ or $X_{4}$ may be chosen as the adjustable model as they are dependent on the rotor speed $\left(\omega_{r}\right)$ is shown in Fig.4. However, $X_{4}$ is selected in the adjustable model, as this quantity does not involve flux estimation and any derivative operations.

\section{SIMULATION RESULTS}

The 5-phase inverter fed induction motor model is simulated to investigate the performance of the drive under varying loads. The parameter of the $1 \mathrm{hp}$ induction motor which is given in Appendix is used for simulation. The SPWM technique is used to generate pulses for inverter as it is effective in terms of THD and fundamental voltage. The open loop results of output voltage, current, torque and speed are observed for rated torque conditions as shown in Fig.5.
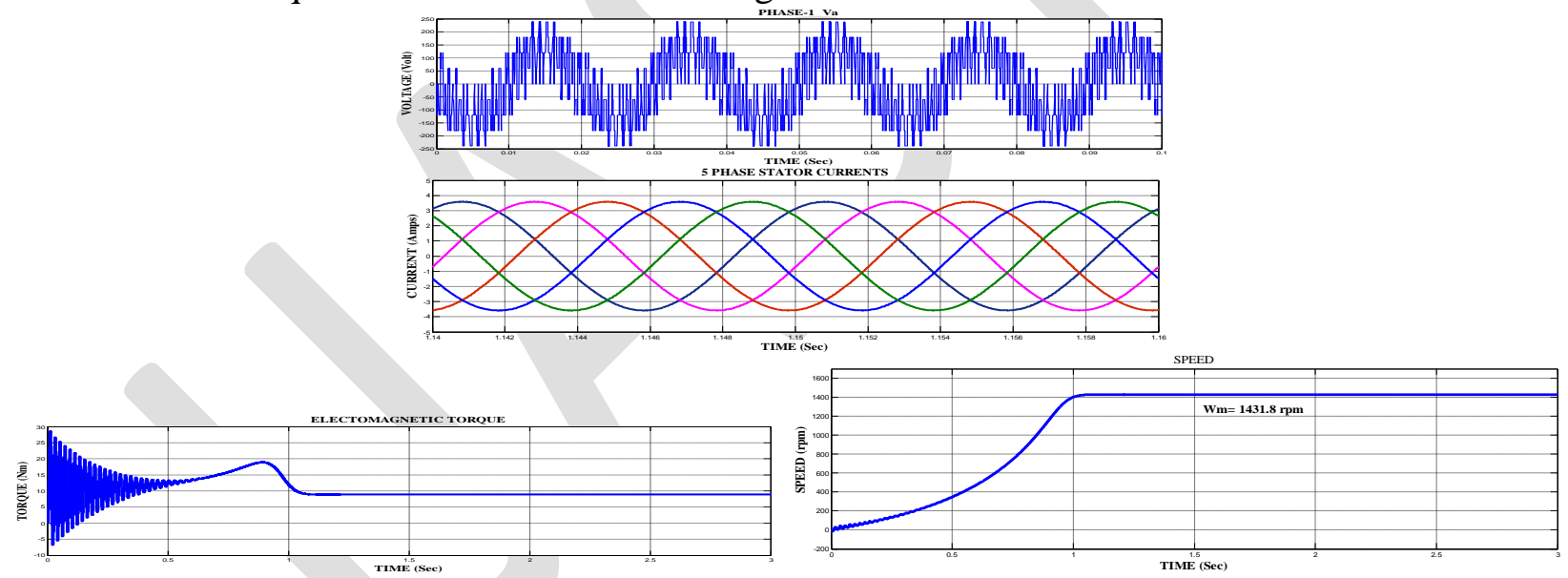

Fig.5. open loop results of 5-phase inverter fed induction motor drive

IFOC controller is designed for the drive along X-MRAS to estimate its speed. Simulation study is performed at different speed and load conditions as follows

\section{a) Fixed reference speed with fixed load}

The reference speed is set $150 \mathrm{rad} / \mathrm{sec}$ and the machine is operated under full load torque condition. Estimated speed tracks the actual speed in turn tracking the set speed is shown in Fig.6. 

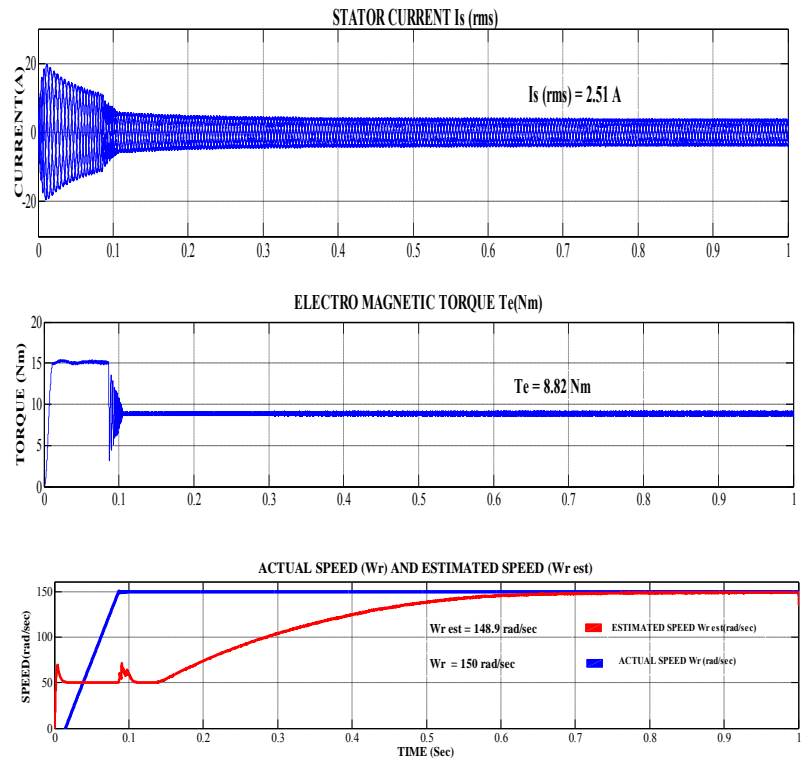

Fig.6. Simulation Results for the IFOC Five Phase Drive at Full Load

\section{b) Fixed reference speed at variable load}

Fig. 7 shows the reference speed is set $150 \mathrm{rad} / \mathrm{sec}$ and the load is varied in steps, as there is a change in load the stator current varies with load and electromagnetic torque follows the load torque. The estimated speed and actual speed tracks the set speed.
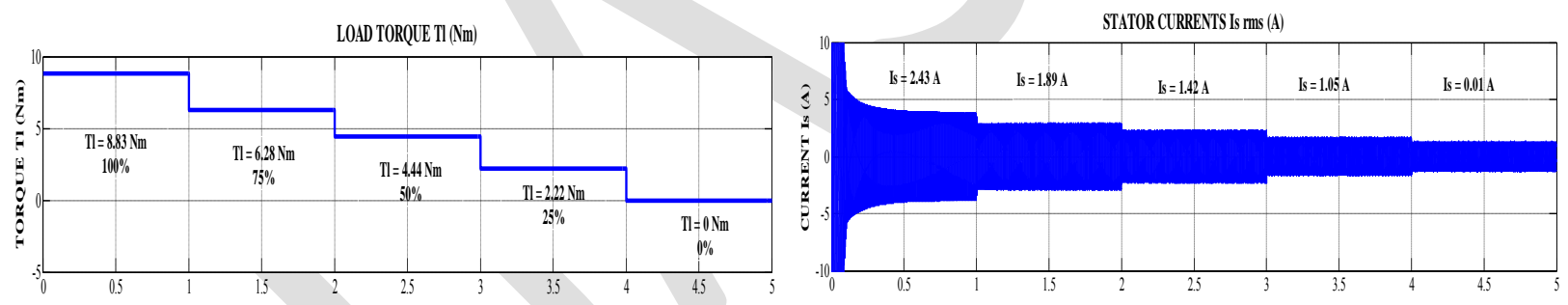

STATOR VOLTAGE Vs (V)
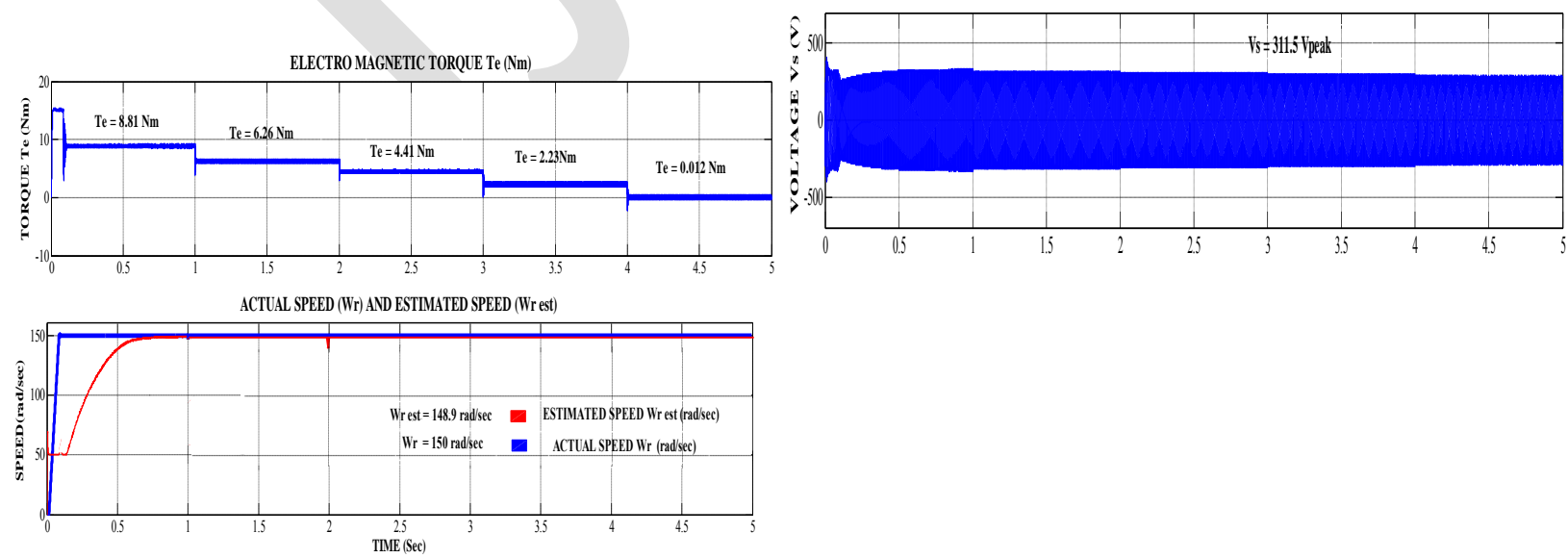

Fig.7. Simulation Results of IFOC Five Phase Drive for Fixed Reference Speed at Variable Load 


\section{c) Variable reference speed at a fixed load}

The load is fixed to $100 \%$ with the reference speed varied in steps. It is seen that the stator current corresponding to full load is maintained. Motor torque follows the load torque. The estimated and actual speed tracks the reference speed is shown in Fig.8.
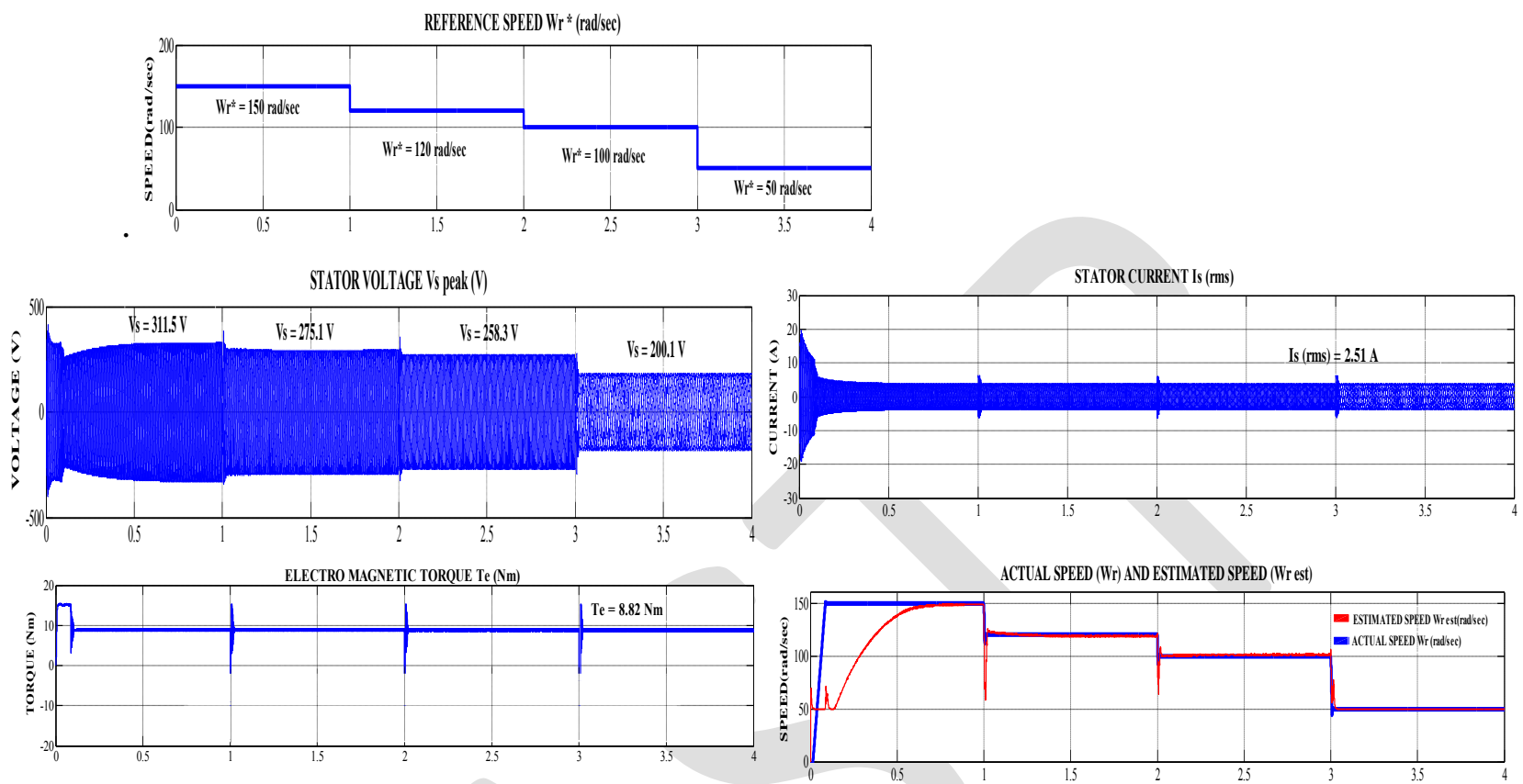

Fig.8. Simulation Results of IFOC Five Phase Drive for Variable Reference Speed at Fixed Load

\section{CONCLUSION}

IFOC controller is designed for the five phase induction motor and an X-MRAS is designed to estimate its speed instead of sensing. The estimated speed follows the actual speed which in turn is tracking the reference speeds from no load to full load. Its accuracy is determined by calculating the steady state error between actual and estimated speed. Steady state error calculated is less than $1 \%$ at both no load and full load conditions; this exhibits the accuracy in estimation. In Sensor based vector control speed encoders/tacho generators are used to sense the rotor speed this reduces the robustness and reliability of the system. Sensor less vector control eliminates the cost of sensors and its maintenance thus increasing reliability.

\section{APPENDIX}

PARAMETERS OF FIVE- PHASE INDUCTION MOTOR DRIVE

\begin{tabular}{cc}
\hline Parameters & Values \\
Power & $1 \mathrm{hp}$ \\
Phase & $5-$ phase \\
Frequency & $50 \mathrm{~Hz}$ \\
No. of poles & 4 \\
Stator resistance & $5 \mathrm{ohm}$ \\
$\left(\mathrm{R}_{\mathrm{s}}\right)$ & \\
Rotor resistance & $2.8 \mathrm{ohm}$ \\
\hline
\end{tabular}




\begin{tabular}{cc}
\hline$\left(\mathrm{R}_{\mathrm{r}}\right)$ & \\
$\begin{array}{c}\text { Stator leakage } \\
\text { inductance }\left(\mathrm{L}_{\mathrm{ls}}\right)\end{array}$ & $0.01759 \mathrm{H}$ \\
$\begin{array}{c}\text { Rotor leakage } \\
\text { inductance }\left(\mathrm{L}_{\mathrm{lr}}\right)\end{array}$ & $0.01759 \mathrm{H}$ \\
$\begin{array}{c}\text { Mutual inductance } \\
\left(\mathrm{L}_{\mathrm{m}}\right)\end{array}$ & $0.12 \mathrm{H}$ \\
Inertia $(\mathrm{J})$ & 0.01 \\
Friction $(\mathrm{F})$ & $\mathrm{kg} . \mathrm{m}^{\wedge} 2$ \\
\hline
\end{tabular}

\section{REFERENCES}

[1] G.Renukadevi and K.Rajambal, "Performance Investigation of Multi-Phase VSI with Simple PWM Switching Techniques" International journal of Engineering TRANSACTIONS C: Aspects, Vol. 26, No. 1, 2012, pp. 289-296.

[2] E.Levi, "Multiphase electric machines for variable-speed applications,"IEEE Trans. Ind. Electron., vol. 55, no. 5, pp. 1893-1909, May 2008.

[3] B. Bose, Power Electronics and AC Drives. Englewood Cliffs, NJ: $\quad$ Prentice-Hall, 1986.

[4] G. K. Singh, "Multi-phase induction machine drive research-A survey," Elect. Power Syst. Res., vol. 62, pp. 139-147, 2002.

[5] Kestelyn, X., Semail, E., and Hautier, J.P.: 'Vectorial multi- machine model for a five-phase machine'. Proc. Int. Conf. on Electrical Machines ICEM. Bruges, Belgium, 2002, CD-ROM paper 394.

[6] J. W. Kolar, H. Ertl, and F. C. Zach, "Influence of modulation method on the conduction and switching losses of a PWM converter system," IEEE Trans. Ind. Appl., vol. 27, no. 6, pp. 1063 1075, Nov./Dec. 1991.

[7] Singh G. K., Nam K., Lim S. K. A Simple Indirect Field-Oriented Control Scheme for Multiphase Induction Machine// Industrial Electronics, IEEE Transactions on, 2005. - Vol.52. - No. 4. - P. 11771184.

[8] "Modeling and control of multi-phase induction machine with structural unbalance, Part II: Fieldoriented control and experimental verification," IEEE Trans. Energy Conv., vol. 11, no. 3, pp. 578584, Sep. 1996.

[9] Zhao Y, Lipo TA. Modeling and control of multi-phase induction machine with structural unbalance, Part I Machine modeling and multi-dimensional current regulation. IEEE Trans 1996;EC-11(3):570 7.

[10]R. Ortega and D. Taoutaou, "Indirect field oriented speed Regulation for induction motors is globally stable," IEEE Trans.Ind. Electron., vol. 43,pp. 340-341, Apr. 1996.

[11]K.Venkateswarlu , G.Sandeep, N.Srinivas, K. Damodara Reddy , A.Ramakrishna, "Speed Sensorless Sliding Mode Control of Induction Motor Using Simulink," IOSR Journal of Electrical and Electronics Engineering (IOSR-JEEE), Volume 6, Issue 2 (May. - Jun. 2013), PP 50-56

[12]A. V. Ravi Teja, Chandan Chakraborty, Suman Maiti, "A New Model Reference Adaptive Controller for Four Quadrant Vector Controlled Induction Motor Drives", IEEE Trans on Ind Electronics, Vol. 59, No. 10, October 2012. 
[13]Colin Schauder,"Adaptive Speed Identification for Vector Control of induction Motors Without Rotational Transducers",IEEE Trans on Ind Applications, Vol.28,No.5,Sept/Oct 1992.

[14]Kottala Kiran Kumar, Sasikanth.S, Dinesh.L,"Simulation of Sensorless Motor Based on Model Reference Adaptive System (MRAS)", IJEREA, Vol.2, Issue 6, November-December 2012, pp.255260.

[15]G. Pydiraju, M. Daivaasirvadam, "Sensorless Speed Control of Induction Motor Using MRAS" IJRTE, Vol.1, Issue 5, November 2012.
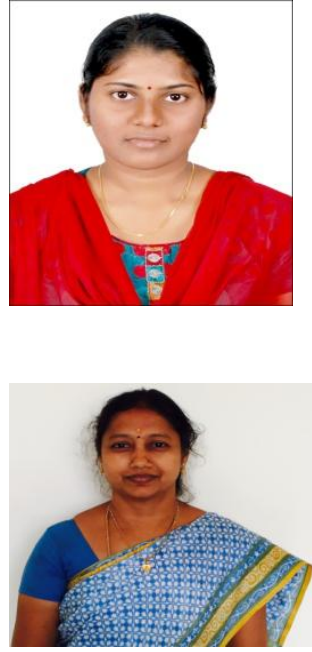

M.Sowmiya received her Undergraduate Degree in Electrical \& Electronics Engineering from Sri Manakula Vinayagar Engineering College in 2011, M. Tech in Electrical Drives \& Control from Pondicherry Engineering College in 2013. She is pursing Ph.D in the area of Multi-phase drive system in the Department of Electrical and Electronics Engineering at College of Engineering, Anna University, Chennai. Her field of interest is Electrical Machines, Power Electronics, Advanced Controllers and AI Techniques.

G. Renuka Devi received her Undergraduate Degree in Electrical Engineering from The Institution of Engineers, India in 2006 and M.Tech, Ph.D in Electrical and Electronics Engineering from Pondicherry Engineering College in 2009 \& 2016. She is working as Associate professor in the Department of Electrical and Electronics Engineering in Manakula Vinayagar Institute of Technology, Puducherry. Her field of interest is Power Electronics, Drives and Control, AI Techniques and Control System. She has published papers in International journals and conferences in the field of Electrical Drives and Power Electronics. 